\title{
M-Phase Promoting Factor
}

National Cancer Institute

\section{Source}

National Cancer Institute. M-Phase Promoting Factor. NCI Thesaurus. Code C28557.

M Phase-Promoting Factor is a protein kinase complex that drives both the mitotic and meiotic cycles in all eukaryotic organisms. In meiosis it induces immature oocytes to undergo meiotic maturation. In mitosis it has a role in the G2/M phase transition. Once activated by CYCLINS; MPF directly phosphorylates some of the proteins involved in nuclear envelope breakdown, chromosome condensation, spindle assembly, and the degradation of cyclins. The catalytic subunit of MPF is PROT EIN P34CDC2. 